\title{
Sexual Orientation and Job Satisfaction: Survey-Based Evidence from Sweden
}

\author{
Lina Aldén ${ }^{1}$ (D) Mats Hammarstedt ${ }^{1,2} \cdot$ Hanna Swahnberg ${ }^{1}$
}

Published online: 8 January 2020

(C) The Author(s) 2020

\begin{abstract}
We present results from a unique nationwide survey conducted in Sweden on sexual orientation and job satisfaction. Our results show that gay men are more likely to be very satisfied with their job than heterosexual men, both in general and with different aspects of the job. In contrast, lesbians appear less satisfied with their job in general and with promotion prospects than heterosexual women. Among women, we find no differences in the probability of being very satisfied with the job by sexual orientation. However, the issue of sexual orientation and job satisfaction is complex since gay men, despite that they more often are very satisfied with the job, like lesbians find their job more mentally straining than heterosexuals. We conclude that gay men and lesbians are facing other stressers at work than heterosexuals do. We also conclude that the worker's own expectations about the job and possibilities to fulfill career plans may be possible driving forces to our results. Previous research has documented discrimination against gay males and lesbians in hiring. Our results underline that measures to prevent discrimination in hiring is not enough to create an equal working life for homosexuals and heterosexuals. Measures within the workplace are also needed.
\end{abstract}

Keywords Job satisfaction · Sexual orientation · Discrimination · Gender · Earnings

JEL $\mathrm{J} 28 \cdot \mathrm{J} 15 \cdot \mathrm{J} 71$

\section{Introduction}

There is a large body of literature on differences in labour market outcomes due to sexual orientation. Most of the research focuses on earnings and typically shows that

Lina Aldén

lina.alden@lnu.se

1 Linnaeus University, SE-351 95 Växjö, Sweden

2 Research Institute of Industrial Economics, SE-102 15 Stockholm, Sweden 
gay males earn less than heterosexual males and that lesbians earn about the same or more than heterosexual females. ${ }^{1}$ Many studies also document that gay males and lesbians are discriminated against in hiring (Adam 1981; Hebl et al. 2002; Weichselbaumer 2003, 2004; Drydakis 2009, 2011; Ahmed et al. 2013a). There is also survey-based evidence that points at discrimination and harassment due to sexual orientation in the workplace. For example, in a review of US studies, Badgett et al. (2007) find that between 15 and $43 \%$ of surveyed lesbian, gay, and bisexual (LGB) individuals reported workplace discrimination. A large-scale EU LGBT survey shows that about $20 \%$ of the lesbian, gay, bisexual, and transgender respondents in the EU felt discriminated against at work, with national rates ranging from $11 \%$ for Denmark to 30\% for Cyprus (European Union Agency for Fundamental Rights 2013). Despite this, less attention has been paid to the extent to which sexual orientation affects subjective well-being at work (i.e., job satisfaction).

From a more general perspective, job satisfaction is important as a measure of individual well-being and thus in showing how welfare is distributed across groups and individuals (Clark 1996). In addition, previous research has shown that job satisfaction is related to worker behaviour. For example, Freeman (1978) and Green (2010) find that low job satisfaction is associated with increased job mobility (i.e., quitting a job) while Drago and Wooden (1992) identify a negative correlation with absenteeism. Other research suggests that greater job satisfaction is associated with higher productivity (e.g., Judge et al. 2001; Patterson et al. 2004). In that sense, studying job satisfaction adds to our knowledge of worker behaviour (Clark 1996).

The empirical evidence on job satisfaction and sexual orientation is small, but growing, and rather mixed. Using an Australian sample of young women, Carpenter (2008b) finds that lesbians are less satisfied with their job than heterosexual females. Drydakis (2012) studies differences in three dimensions of job satisfaction among males in Greece: satisfaction with total pay, promotion prospects, and respect from one's supervisor. The results show that gay males are less satisfied than heterosexual males with all three of these job facets. In a related study, Drydakis (2015) uses a random sample of households in Athens that also enables a comparison by gender and between gay males and lesbians who have disclosed their sexual identity at work and those who have not. In line with the previous study, he finds that gay males and lesbians are less satisfied than heterosexuals with all three dimensions of the job. They are also less satisfied with the job in general. The results suggest that disclosure increases job satisfaction; gay males and lesbians who are open about their sexual identity at work have a higher level of job satisfaction than those who are not. Leppel (2014) provides evidence on differences in job satisfaction for both gays and lesbians using Canadian data and studies differences by marital status. She finds that both unmarried gay men and unmarried lesbians are less satisfied with the job than their heterosexual counterparts, whereas no such difference is found among people who are married. In contrast, using US data, Leppel and Clain (2015) find no difference in job satisfaction by sexual orientation among unmarried males and females. Results reveal,

\footnotetext{
${ }^{1}$ This pattern has been documented in different countries and remained stable over time. See Badgett (1995, 2001), Klawitter and Flatt (1998), Allegretto and Arthur (2001), Clain and Leppel (2001), and Carpenter (2005) for studies from the US; Carpenter (2008a) for a study from Canada; Arabsheibani et al. (2004, 2005) for studies from the UK; Plug and Berkhout (2004) for a study form the Netherlands; Ahmed and Hammarstedt (2010), Ahmed et al. 2011a, 2013b) and Hammarstedt et al. (2015) for studies from Sweden.
} 
however, that both married gay men and lesbians are less satisfied with their job than their heterosexual counterparts, and that married lesbians have lower job satisfaction than unmarried lesbians.

In this paper we explore the extent to which job satisfaction differs by sexual orientation in Sweden. For this purpose, we combine unique survey data with highquality register data from Statistics Sweden. The survey was conducted in 2016 to obtain data about workers' job satisfaction. The survey was sent to a random sample of employees aged 25-64 who were resident in Sweden in 2016. Sexual orientation was identified using register data on civil status. In 1995 gay males and lesbians in Sweden were granted the right to enter registered partnership, and since 2009 they also have the right to marry in the Church of Sweden. Using this information we define gay males/ lesbians as males/females who in 2016 were in a registered partnership or married to a person of the same sex. We define heterosexuals as individuals who are married to a person of the opposite sex.

In the survey respondents were asked about the extent to which they were satisfied with their job in general but also with the pay, promotion prospects, relation to the their immediate supervisor, and relation to their nearest colleagues. Respondents were also asked if their job was mentally straining and if the job was stressful. In addition, respondents were asked about their general and mental health and number of working hours in an average week. The survey thus provides rich and varied information about employees' subjective well-being at work. From the LISA database at Statistics Sweden, we collect information about respondents' age, birth region, educational attainment, region of residence, and job characteristics (firm size, sector of employment and business line) for 2016 .

The paper contributes to the literature in several ways. First, this is a nationwide study of both gay men and lesbians. Further, the study is based on a larger sample than those used in previous work. A further advantage of our study is that the rich information about satisfaction with various aspects of their job allows us to explore differences in job satisfaction by sexual orientation along several dimensions for both genders. As pointed out by Skalli et al. (2008), overall job satisfaction reflects various features of an individuals' job. Finally, our study is conducted in Sweden, a country where attitudes towards homosexuals tend to be more positive than in most other countries. $^{2}$

We have to acknowledge some limitations with our study. We define homosexuals as individuals who are married to, or registered partner to, a person of the same sex. This information is obtained from public registers at Statistics Sweden and has its limitations. First, using this definition rather than a self-reported measure of sexual orientation implies that we might mix bisexuals with homosexuals. Further, the use of this definition implies that our results are only representative for individuals who are married. However, information from public registrers is the best measure of sexual orientation we can use in absence of a self-reported measure.

Our results reveal a complex pattern. We find that gay men, on average, a more likely to be very satisfied with their job, both in general and with different aspects of their job, than heterosexual men. In contrast, for lesbians we find no statistically

\footnotetext{
${ }^{2}$ The European Union Agency for Fundamental Rights (2013) shows that Sweden is one of the most tolerant countries of homosexuals in Europe.
} 
significant differences in the probability of being very satisfied with their job compared to heterosexual females. Instead lesbians are less with their job in general and also with their wages and promotion prospects. Further, both gay men and lesbians are more likely than heterosexuals to perceive their job as mentally straining. An important conclusion from our study is that there are differences between gay men and lesbians as regards job satisfaction, and that the worker's own expectations about the job and possibilities to fulfill career plans may be possible driving forces behind the results that we observe.

The remainder of this paper is organised as follows: Section 2 explains why we can expect job satisfaction to vary with sexual orientation. In Section 3 we present the survey; descriptive statistics are presented in Section 4. The empirical strategy is presented in Section 5 and Section 6 presents the results. Finally, a discussion and conclusions are presented in Section 7.

\section{Why Should We Expect Job Satisfaction to Vary with Sexual Orientation?}

We can put up different hypotheses regarding differences in job satisfaction due to sexual orientation. First, such differences may be due to the existence of sexual prejudice and discrimination. There is a large body of research, particularly in social psychology, that offers evidence of sexual prejudice in a variety of contexts (Ahmad and Bhugra 2010; Bhugra 1987). When sexual prejudices are put into action they result in discrimination based on sexual orientation, which may decrease job satisfaction among gays and lesbians. A number of studies have documented discrimination in hiring against gays and lesbians (Adam 1981; Hebl et al. 2002; Weichselbaumer 2003, 2004; Drydakis 2009, 2011; Ahmed et al. 2013a), and there is also survey-based evidence suggesting that there is discrimination based on sexual orientation in the workplace (Badgett et al. 2007). If this is the case, we may expect lower job satisfaction among gay men and lesbians than among heterosexuals. In addition, research in social psychology shows that the attitudes against gay men are much more hostile than are attitudes against lesbians (Herek 2002; Kite and Whitley 1996). As a results, we may also expect job satisfaction to differ also between gay males and lesbians.

Further, according to Locke's range-of-affect theory, a worker's satisfaction with any facet of the job, such as pay and prospects for advancement, depends on the value placed on that facet (facet importance) and the extent to which the amount of a particular job facet that the worker desires differs from the perceived or actual amount (the have-want discrepancy) (Locke 1976, 1984; McFarlin et al. 1995). ${ }^{3}$ The higher value the worker places on a particular job facet, the stronger the affective reaction to that facet is expected to be. The reaction can range from extreme dissatisfaction to extreme satisfaction. The affective reaction is also expected to be stronger, the greater the gap between current job situation and what the worker wants and desires in the job. For example, if a worker places a high value on earnings but earnings are below the worker's expectations, his/her reported job satisfaction is predicted to be low.

\footnotetext{
${ }^{3}$ Deardorff and Stafford (1976) formalized the idea of jobs having different facets into an equilibrium model.
} 
The value placed on different facets of the job may be of importance for differences in job satisfaction between gay men, lesbians and heterosexuals. Research shows that gay men are at an earnings disadvantage compared to heterosexual males. Given that gay men expect to earn the same as heterosexual males and given that earnings are important for job satisfaction, this suggests that gay males may report lower job satisfaction than heterosexual males due to a higher discrepancy between what they have and what they want in a job. In contrast, lesbians are at an earnings advantage, suggesting that because of their higher earnings and possibly brighter promotion prospects, they may report higher job satisfaction than heterosexual females. ${ }^{4}$

Differences in expectations may also result in differences in job satisfaction between the groups. The existence of sexual orientation discrimination may decrease the expectation that gay men and lesbians have of various job characteristics. Studies of gender and job satisfaction have shown that women report higher job satisfaction than men despite lower earnings and fewer chances of promotion. This may be because women have reached a better position on the labour market than they have expected (Clark 1997; Sousa-Poza and Souza-Posa 2003; Bender et al. 2005; Gazioglu and Tansel 2006). Similar mechanisms might be at work regarding sexual orientation. Low expectations may lead gay men and lesbians to report higher job satisfaction than heterosexuals. However, previous research argues that lesbians are more careeroriented and less focused on family and children than heterosexual females (Peplau and Fingerhut 2004; Baert 2014). If so, this may lead to lesbians having higher expectations for wages and promotion than heterosexual females. If discrimination keep lesbians from fulfilling their career plans, this may lead to lesbians reporting lower job satisfaction than heterosexual females.

Closely related to the earnings differentials are labour supply differentials. Research shows that there are differences in labour supply due to sexual orientation (Tebaldi and Elmslie 2006; Klawitter 2011; Martell 2014; Martell and Roncolato 2016; Dilmaghani 2018). Working many hours may reduce job satisfaction, and we may expect that differences in job satisfaction between gay males, lesbians and heterosexuals may arise due to differences in their number of hours worked.

Another factor of importance for differences in job satisfaction due to sexual orientation can be found in the existence of family friendly work practices, such as parental leave and provision for childcare (Heywood et al. 2007; Green and Heywood 2011). Such work practices have increased during recent decades and can be expected to be positively related to job satisfaction (Saltzstein et al. 2011). Since heterosexuals more often have children than gay men and lesbians, such family friendly practices can be expected to increase job satisfaction more for heterosexuals than for gay males and lesbians. Furthermore, lesbians are more likely to have children than gay men (Aldén et al. 2015). Thus, we can expect the existence of family friendly work practices to result in differences in job satisfaction by sexual orientation but also between males and females.

Research shows that gays and lesbians tend to sort into unprejudiced occupations (i.e., they anticipate workplace discrimination in some occupations and therefore avoid

\footnotetext{
${ }^{4}$ Ahmed et al. (2011b) have shown that lesbians are over-represented in occupations demanding high education and management positions in Sweden.
} 
them). ${ }^{5}$ This sorting is particularly strong for gay and lesbian workers who have disclosed their sexual identities (Plug et al. 2014). In addition, Ahmed et al. (2013a) find that gay men are discriminated against in male-dominated occupations and lesbians are discriminated against in female-dominated occupations, and that discrimination was less prevalent in the public sector than in the private sector. This suggests that gay and lesbian workers who work in more tolerant workplaces are likely to report a higher job satisfaction than gay and lesbian workers in less tolerant ones.

To sum up, we have reason to expect that job satisfaction varies by sexual orientation. We may also expect the impact of the relationship between job satisfaction and sexual orientation to differ by gender and by occupation. However, whether gay men and lesbians can be expected to report higher or lower job satisfaction than heterosexuals cannot be determined a priori since different mechanisms work in different directions. One may hypothesise that gay men and lesbians have lower job satisfaction than heterosexuals due to certain circumstances, but the opposite may as well occur due to other circumstances. In the end it is an empirical question.

\section{The Survey}

In order to obtain data on workers' job satisfaction, we conducted a survey administrated by Statistics Sweden between March and May 2016. We identified the individual's sexual orientation by using information about civil status available in Swedish register data. Since 1995, gay males and lesbians in Sweden have had the right to enter registered partnership and since 2009 they have the right to marry in the Church of Sweden. Using this information, we define lesbians/gay males as individuals who in 2016 either were in a registered partnership or married to a person of the same sex. Correspondingly, we define heterosexuals as individuals who are married to a person of the opposite sex. ${ }^{6}$ The population for the survey comprised all individuals, aged 25-65, who were married or a registered partner and resident in Sweden in 2016, and who were registered as wage-employed in November in 2014. We use information on labour market activity in 2014, since this was the most recent data available at Statistics Sweden at the time of the survey.

From this population, we drew a stratified random sample. More specifically, the population was stratified on gender, the partner's/spouse's gender, and whether or not the partner/spouse was in the survey population. The purpose of the latter stratification was to avoid including both partners/spouses in a couple in the survey sample. For the couples where both partners/spouses were in the population we used the following procedure: First the couples were randomly drawn from the population and then one partner/spouse in each couple was randomly selected from those couples. This implies that among gay males, lesbians, heterosexual males, and heterosexual females we created two strata: a) individuals whose spouse/partner was included in the population and b) individuals whose spouse/partner was not included in the population. Thus, in total eight $(4 \times 2)$ strata were created. The total sample size was 5000 individuals: four

\footnotetext{
${ }^{5}$ For a discussion about job satisfaction and gender segregation, see i.e. Bender et al. (2005).

${ }^{6}$ The data does not enable an identification of lesbians and gay males who are cohabiting or single. See Ahmed and Hammarstedt (2010) for a further discussion of this definition.
} 
groups - gay males, lesbians, heterosexual males, and heterosexual females - of 1250 members. 7

In the survey, the respondents were asked about the extent to which they were satisfied with various aspects of their job. On a five-point scale, ranging from very satisfied to very dissatisfied, they were asked to rank their job satisfaction, their satisfaction with their earnings, prospects for promotion, relationship to their immediate manager, and their satisfaction with the relationship with their nearest colleagues. They were also asked if they perceived their job as mentally straining (yes or no) or stressful (yes or no). In addition, we asked the respondents to rank their general health on a five-point scale from very good to very poor. To get information about the respondents' mental health we asked if they during the last 12 months had experienced fatigue, sleeping problems, anxiety or depression. Here, they could answer that they had had serious problems, some problems or no problems. Finally, we asked about number of working hours per week. ${ }^{8}$

For all strata the response rate was a relatively high average of $55.4 \%$. For gay males it was $61.9 \%, 54.8 \%$ for lesbians, $49.0 \%$ for heterosexual males, and $55.8 \%$ for heterosexual females. We excluded individuals who have missing values or ambiguous answers to the survey questions. This reduced the sample to 2493 individuals: 703 gay males, 626 lesbians, 549 heterosexual males, and 626 heterosexual females.

To the survey data, we link high-quality register data from Statistics Sweden for the year 2014. From this data source we obtained information about individual and job characteristics, including educational attainment, country of birth (on a regional level), region of residence in Sweden, labour earnings, sector of employment, business line, and number of employees at the workplace. Access to these variables, in addition to those from the survey, enables us to consider many factors that may influence individual job satisfaction apart from sexual orientation.

Table 6 in the Appendix compares respondents with non-respondents, and individuals included in the total sample by gender, age, earnings, and region of residence (columns 1-3). This information was provided by Statistics Sweden. Based on register data we have also produced the corresponding information for the population from which the sample was drawn (column 4). Overall, there are no striking differences among the different groups, except that non-respondents are slightly more likely to be young and low-income earners. Table 7 in the Appendix presents descriptive statistics for the total population of the control variables, used in the empirical analysis, which could be obtained from register data. A comparision with the corresponding statisics for respondents presented in Table 1 reveals no striking differences. Thus, the respondents to the survey appear to be representative for the total population.

\section{Descriptive Statistics}

Table 1 presents descriptive statistics for the individuals in the survey. From the table it emerges that gay men and lesbians on average are somewhat younger than heterosexual

\footnotetext{
${ }^{7}$ We selected the sample size based on a power calculation. Given a 5 percentage point difference in the probability of being very satisfied with the job based on sexual orientation, a sample of 434 individuals in each groups is required to estimate a statistically significant difference of 5 percentage points at the 5-per cent level with a statistical power of $80 \%$. This corresponds to a response rate in each group of about $35 \%$.

${ }^{8}$ The survey is available form the authors upon request.
} 
Table 1 Descriptive statistics of demographic, health, and job characteristics

\begin{tabular}{|c|c|c|c|c|}
\hline & $\begin{array}{l}\text { Heterosexual } \\
\text { males }\end{array}$ & Gay males & $\begin{array}{l}\text { Heterosexual } \\
\text { females }\end{array}$ & $\begin{array}{l}\text { Lesbian } \\
\text { females }\end{array}$ \\
\hline Age & 50.7 & $48.6^{* * *}$ & 49.5 & $44.1 * * *$ \\
\hline \multicolumn{5}{|l|}{ Education } \\
\hline Primary school & 0.110 & $0.057 * *$ & 0.045 & $0.026^{*}$ \\
\hline Secondary school & 0.370 & $0.317 * *$ & 0.358 & $0.260 * * *$ \\
\hline University & 0.520 & $0.626 * * *$ & 0.597 & $0.714^{* * *}$ \\
\hline Born outside Sweden & 0.145 & $0.204 * * *$ & 0.151 & $0.112 * *$ \\
\hline Metropolitan area & 0.410 & $0.713 * * *$ & 0.378 & $0.563 * * *$ \\
\hline \multicolumn{5}{|l|}{ General health } \\
\hline Very bad & 0.005 & 0.004 & 0.002 & $0.016^{* * *}$ \\
\hline $\mathrm{Bad}$ & 0.035 & 0.034 & 0.067 & 0.069 \\
\hline Neither good nor bad & 0.116 & 0.105 & 0.098 & 0.120 \\
\hline Good & 0.576 & $0.495 * * *$ & 0.537 & 0.542 \\
\hline Very good & 0.267 & $0.361 * * *$ & 0.297 & $0.254 *$ \\
\hline \multicolumn{5}{|l|}{ Mental health } \\
\hline Fatigue & 0.046 & $0.085 * * *$ & 0.136 & $0.177 * *$ \\
\hline Sleeping problems & 0.062 & 0.085 & 0.103 & 0.120 \\
\hline Anxiety & 0.035 & $0.076 * * *$ & 0.080 & $0.134 * * *$ \\
\hline Depression & 0.018 & $0.037 * *$ & 0.030 & $0.061 * * *$ \\
\hline Weekly working hours & 41.1 & 40.4 & 37.3 & 36.8 \\
\hline Annual earnings, SEK & 486,800 & $450,700 * *$ & 350,000 & 335,500 \\
\hline \multicolumn{5}{|l|}{ \# of employees at workplace } \\
\hline $0-9$ & 0.134 & 0.124 & 0.102 & 0.098 \\
\hline $10-19$ & 0.116 & 0.104 & 0.122 & 0.140 \\
\hline $20-49$ & 0.199 & $0.142 * * *$ & 0.210 & $0.155 * *$ \\
\hline $50-249$ & 0.297 & 0.306 & 0.356 & 0.320 \\
\hline$>249$ & 0.254 & $0.324 * * *$ & 0.210 & $0.286^{* * *}$ \\
\hline \multicolumn{5}{|l|}{ Business line } \\
\hline Manufacturing & 0.250 & $0.037 * * *$ & 0.061 & 0.054 \\
\hline Construction & 0.087 & $0.013 * * *$ & 0.011 & 0.016 \\
\hline Trade & 0.100 & 0.096 & 0.100 & 0.081 \\
\hline Information and communication & 0.058 & 0.061 & 0.026 & 0.042 \\
\hline Transport and warehousing & 0.075 & 0.062 & 0.023 & 0.029 \\
\hline $\begin{array}{l}\text { Finance, insurance, business } \\
\text { services }\end{array}$ & 0.097 & 0.095 & 0.084 & $0.059 *$ \\
\hline Public administration & 0.067 & $0.044 *$ & 0.033 & 0.050 \\
\hline Law, business, and technology & 0.058 & $0.099 * * *$ & 0.108 & $0.144 *$ \\
\hline Education & 0.079 & $0.108^{*}$ & 0.236 & $0.184 * *$ \\
\hline Health care and social services & 0.064 & $0.225 * * *$ & 0.256 & 0.247 \\
\hline Services & 0.018 & $0.051 * * *$ & 0.027 & 0.043 \\
\hline Other & 0.047 & $0.108 * * *$ & 0.035 & 0.051 \\
\hline Public sector & 0.276 & $0.449 * * *$ & 0.579 & 0.591 \\
\hline Observations & 549 & 703 & 615 & 626 \\
\hline
\end{tabular}

The statistics are weighted and adjusted for sampling design using Stata svy commands. ***, **, and * indicate statistical significance of difference by sexual orientation within gender at the 1-, 5-, and $10 \%$ level 
males and females. Heterosexual men have about $8 \%$ higher yearly income than gay men; the income difference between heterosexual women and lesbians is around $4 \%$ but statistically insignificant. Furthermore, the share with university education is higher among gay men and lesbians than among heterosexuals. This is consistent with findings in previous studies by Ahmed and Hammarstedt (2010) and Ahmed et al. 2011a, b, 2013b).

Turning to health-related variables, more than $36 \%$ of gay men answered that their general health was very good. The corresponding share among heterosexual men was slightly less than $27 \%$. Among lesbians somewhat more than $25 \%$ answered that their general health was very good, while this share amounted to about $30 \%$ among heterosexual females. Almost 9\% of the lesbians answered that their general health was bad or very bad. This could be compared to around $7 \%$ among heterosexual women. Among gay men and heterosexual men this share amounted to around $4 \%$.

More women than men reported problems with mental health. In addition, in line with previous researchs gay males and lesbians appear to suffer from mental issues to a larger extent than heterosexuals (e.g., Meyer 2003; Chakraborty et al. 2011; Bränström 2017). Over $17 \%$ of the lesbians suffered from fatigue while the corresponding share among heterosexual females was slightly more than $13 \%$. Among gay men somewhat over $8 \%$ suffered from fatigue while the corresponding share among heterosexual men was somewhat less than $5 \%$.

Among lesbians $12 \%$ reported sleeping problems while the corresponding share among heterosexual women was over $10 \%$. Almost $9 \%$ of the gay men suffered from sleeping problems while less than $7 \%$ of the heterosexual men answered that they suffered from sleeping problems.

Slightly more than $13 \%$ of the lesbians answered that they had anxiety problems, while about $8 \%$ of the heterosexual women did. Among heterosexual men less than $4 \%$ reported anxiety problems while the corresponding share among gay men was almost $8 \%$. Finally, more than $6 \%$ of the lesbians reported having depression, which is about twice as large share than the share in the other groups.

It is also worth noting that the number of weekly working hours were highest among heterosexual and gay men. Heterosexual females reported that they worked slightly more than lesbian females. Finally, almost $60 \%$ of the women were working in the public sector. Among gay men around $45 \%$ were working in the public sector and $28 \%$ of the heterosexual men were working in that sector.

Descriptive statistics regarding variables measuring job satisfaction are presented in Table 2. The first variable presented is the answer to the question How satisfied are you with your job? Approximately $31 \%$ of gay men answered that they were very satisfied with their job; the corresponding share among heterosexual men was about $26 \%$. Around $30 \%$ of the lesbians were very satisfied with their job and the comparable share among heterosexual women was a bit over $27 \%$. However, this difference is not statistically significant. Furthermore, $43 \%$ of the lesbians reported that they were satisfied with their job while the corresponding share among heterosexual females was $51 \%$. Around $14 \%$ of the lesbians - a rather large per centage - reported being dissatisfied or very dissatisfied with their job, compared to less than $10 \%$ of heterosexual women.

Turning to the question How satisfied are you with your wage? it emerges that $16 \%$ of the gay men and $12 \%$ of the heterosexual men are very satisfied. Among lesbians, 
Table 2 Descriptive statistics of job satisfaction measures

\section{Heterosexual males Gay males Heterosexual females Lesbian females}

\section{Job satisfaction}

Very dissatisfied

0.021

Dissatisfied

0.065

0.033

0.017

$0.042 * * *$

Neither satisfied nor dissatisfied $\quad 0.164$

Satisfied

0.494

Very satisfied

0.257

0.089

0.077

0.100

$0.117 * *$

0.125

0.121

0.453

0.510

$0.433 * * *$

Satisfaction with wages

Very dissatisfied

0.042

$0.307 * *$

0.271

0.303

Dissatisfied

0.149

Neither satisfied nor dissatisfied

0.242

Satisfied

0.451

Very satisfied

0.116

0.058

0.059

0.069

0.126

0.168

$0.209 *$

$0.191 * *$

0.244

$0.183 * * *$

0.464

0.413

0.407

$0.161 * *$

0.116

0.131

Satisfaction with promotion prospects

$\begin{array}{ll}\text { Very dissatisfied } & 0.047 \\ \text { Dissatisfied } & 0.138 \\ \text { Neither satisfied nor dissatisfied } & 0.419 \\ \text { Satisfied } & 0.297 \\ \text { Very satisfied } & 0.100\end{array}$

$0.064 \quad 0.037$

$0.087 * * *$

0.145

0.125

$0.169 * *$

$0.358 * * \quad 0.423$

$0.355 * *$

0.287

0.288

0.251

$0.146^{* * *}$

0.128

0.137

Satisfaction with nearest manager

Very dissatisfied

0.058

0.070

0.057

0.075

Dissatisfied

0.107

0.100

0.111

0.113

Neither satisfied nor dissatisfied

0.165

Satisfied

0.358

0.132

0.141

0.130

0.327

0.367

0.332

$0.371 * *$

0.324

0.350

Satisfaction with nearest colleagues

$\begin{array}{ll}\text { Very dissatisfied } & 0.004 \\ \text { Dissatisfied } & 0.015 \\ \text { Neither satisfied nor dissatisfied } & 0.105 \\ \text { Satisfied } & 0.419 \\ \text { Very satisfied } & 0.457 \\ \text { Job mentally straining } & 0.685 \\ \text { Job stressful } & 0.861 \\ \text { Observations } & 549\end{array}$

$\begin{array}{ll}0.003 & 0.002 \\ 0.030 * & 0.029 \\ 0.101 & 0.090 \\ 0.365 * & 0.391 \\ 0.500 & 0.488 \\ 0.775 * * * & 0.719 \\ 0.913 * * * & 0.921 \\ 703 & 615\end{array}$

$0.013 * *$

0.034

0.078

$0.342 *$

0.533

$0.804 * * *$

0.914

626

Due to that individuals do not have a manager or colleagues, the number of observations for satisfaction with nearest manager and colleagues is slightly lower. The statistics are weighted and adjusted for sampling design using Stata svy commands. $* * *, * *$, and * indicate statistical significance of difference by sexual orientation within gender at the 1-, 5-, and $10 \%$ level

$13 \%$ were very satisfied and almost $12 \%$ of the heterosexual women were very satisfied. The difference is not statistically significant. As with job satisfaction, a relatively large share, $28 \%$, of the lesbians are dissatisfied or very dissatisfied with their wage. 
Among gay men, almost $15 \%$ answered that they were very satisfied with their promotion prospects. Only $10 \%$ of heterosexual men were. Among lesbians, nearly $14 \%$ claimed to be very satisfied. The difference between lesbians and heterosexual women was negligible. Almost $13 \%$ of the heterosexual women indicated that they were very satisfied with their chances of promotion. However, like before, a large share of lesbians were dissatisfied or very dissatisfied with their promotion prospects.

Gay men are more often very satisfied with their managers and with their colleagues than heterosexual men. More than $37 \%$ of the gay men answered that they were very satisfied with their manager. The corresponding figure among heterosexual men was almost $31 \%$. Among women there are no statistically significant differences. More than $50 \%$ of the gay men and nearly $46 \%$ of heterosexual men answered that they were very satisfied with their colleagues. Furthermore, 53\% of the lesbians and $49 \%$ of heterosexual women were very satisfied with their colleagues. These differences are not statistically significant.

Lastly, respondents were asked if their job was mentally straining or not and if they considered their job stressful. More than $80 \%$ of the lesbians answered that their job was mentally straining; among heterosexual women less than $72 \%$ considered their job mentally straining. Among gay men, about $77 \%$ considered their job mentally straining. The comparable share among heterosexual men was about $68 \%$. Somewhat more than $91 \%$ of the lesbians considered their job stressful. The difference compared to heterosexual females is very small. About $91 \%$ of the gay men answered that their job was stressful while $86 \%$ of the heterosexual men answered that their job was stressful.

\section{Empirical Specification}

To identify and explore differences in job satisfaction between gay men and heterosexual men and lesbians and heterosexual women, we estimate two regression models. We start by estimating a set of OLS regressions using the following equation separately by gender:

$$
Z_{i}=\alpha_{0}+\alpha_{1}(\text { Gay } / \text { Lesbian })_{i}+\beta X_{i}+\varepsilon_{i}
$$

The outcome variable, $Z_{i}$, measures satisfaction with the job, the wage, promotion prospects, immediate colleagues, and satisfaction with immediate boss. It ranges from 1 to 5 and takes the value 1 if the individual is very dissatisfied and 5 if the individual is very satisfied. By estimating ordinary least squares (OLS) regressions, we assume that the answers can be treated as cardinal. An alternative, often used in previous research (Carpenter 2008a, b; Drydakis 2012, 2015; Leppel 2014: Leppel and Clain 2015), is to estimate a non-linear model such as ordered probit or logit model, in which case the dependent variable is treated as ordinal. However, it has been shown that assuming that satisfaction answers are cardinally or ordinally comparable yields very similar results (Ferrer-i-Crabonell and Frijters 2004).

$(\text { Gay/Lesbian })_{i}$ is a dummy variable that equals 1 if the individual is a gay male or lebian female, and 0 otherwise. $X_{i}$ is a set of control variables and $\varepsilon_{i}$ is the error term. We estimate three specifications. Specification 1 includes the indicator for whether the individual is gay man/lesbian or not and shows the unconditional differences between 
gay men and heterosexual men and lesbians and heterosexual women. Specification 2 includes controls for individual characteristics that are exogeneously given, i.e. age, age squared, and whether the individual is foreign born or not. Specification 3 add controls for educational attainment (three levels) and region of residence in Sweden (metropolitan area). Specification 3 also include controls for self-reported general and mental health and for job characteristics, (i.e., annual labour earnings, number of weekly working hours, number of co-workers, an indicator for if the individual is employed in the public sector, and controls for the business line in which the individual is employed). We estimate Specification 2 since some of the variables included in Specification 3, such as mental health, may be endogenous and thus so called bad controls.

Second, we estimate a linear probability models (LPM) using the following equation:

$$
\operatorname{Pr}\left(Y_{i}=1\right)=\alpha_{0}+\alpha_{1}(\text { Gay } / \text { Lesbian })_{i}+\beta X_{i}+\varepsilon_{i}
$$

In this case the outcome variable, $Y_{i}$, takes the value 1 if the respondent has answered that he/she is very satisfied with the job, the wage, the promotion prospects, the immediate manager, and the nearest colleagues, and 0 otherwise. Thus, using this model we study differences by sexual orientation in being very satisfied with the different job facets. We also estimate linear probability models to explore differences in the extent to which the job is perceived as mentally straining or stressful. In these cases, the outcome variable takes the value 1 if the individual has answered that his/her job is mentally straining or stressful, and 0 otherwise. We estimate eq. (2) by gender using the three specifications described for eq. (1) above. In all estimations, we weight and adjust the results for sampling design using Stata svy commands.

Since previous research often makes use of an ordered probit model we have also, as a robustness check, estimated eq. (1) using an ordered probit model. In all essentials, we find very similar results (available upon request). As a sensitivity check we have also estimated eq. (2) with two alternative outcome variables. In the first case, the outcome variable takes the value 1 if the respondent has answered that he/she is very satisfied or satisfied with the job, the wage, the promotion prospects, the manager, and the colleagues, and 0 otherwise. In the second case, the outcome variable takes the value 1 if the respondent has answered that he/she is very dissatisfied or dissatisfied with the job, the wage, the promotion prospects, the manager, and the colleagues, and 0 otherwise. The results from these estimations are very much in line with the pattern in main estimations. They are not presented in the paper but are available from the authors upon request.

\section{Results}

\section{Measures of Job Satisfaction}

Tables 3 and 4 present the estimation results for the different measures of job satisfaction for males and females, respectively. If we begin with the OLS estimates for males in Table 3 columns 1-3 in panel A-E, there is no evidence that satisfaction with the job 
Table 3 Linear probability and OLS estimates of different measures of job satisfaction, men

\begin{tabular}{|c|c|c|c|c|c|c|}
\hline & (1) & (2) & (3) & (4) & (5) & (6) \\
\hline Variables & OLS & OLS & OLS & LPM & LPM & LPM \\
\hline \multicolumn{7}{|l|}{ A. Job satisfaction } \\
\hline \multirow[t]{2}{*}{ Gay males } & 0.011 & 0.022 & -0.016 & $0.050 *$ & $0.058 * *$ & 0.025 \\
\hline & $(0.056)$ & $(0.057)$ & $(0.065)$ & $(0.026)$ & $(0.026)$ & $(0.033)$ \\
\hline \multirow[t]{2}{*}{ Constant } & $3.905 * * *$ & $7.476^{* * * *}$ & $5.723 * * *$ & $0.259 * * *$ & $1.840 * * *$ & $1.638^{* *}$ \\
\hline & $(0.040)$ & $(0.981)$ & $(1.384)$ & $(0.019)$ & $(0.571)$ & $(0.719)$ \\
\hline R-squared & 0.000 & 0.019 & 0.223 & 0.000 & 0.019 & 0.128 \\
\hline \multicolumn{7}{|l|}{ B. Satisfaction with wage } \\
\hline \multirow[t]{2}{*}{ Gay males } & 0.088 & 0.095 & 0.128 & $0.042 * *$ & $0.042 * *$ & 0.008 \\
\hline & $(0.060)$ & $(0.061)$ & $(0.079)$ & $(0.019)$ & $(0.020)$ & $(0.027)$ \\
\hline \multirow[t]{2}{*}{ Constant } & $3.451 * * *$ & $3.198 * * *$ & -1.999 & $0.116^{* * *}$ & -0.464 & $-1.705^{* * *}$ \\
\hline & $(0.043)$ & $(1.235)$ & $(1.774)$ & $(0.014)$ & $(0.375)$ & $(0.576)$ \\
\hline R-squared & 0.000 & 0.015 & 0.218 & 0.000 & 0.006 & 0.132 \\
\hline \multicolumn{7}{|c|}{ C. Satisfaction with promotion prospects } \\
\hline \multirow[t]{2}{*}{ Gay males } & 0.024 & 0.025 & -0.019 & $0.038 * *$ & $0.035 *$ & -0.001 \\
\hline & $(0.059)$ & $(0.061)$ & $(0.073)$ & $(0.019)$ & $(0.019)$ & $(0.026)$ \\
\hline \multirow[t]{2}{*}{ Constant } & $3.278 * * *$ & $5.523 * * *$ & 1.848 & $0.105 * * *$ & $0.917 * *$ & 0.369 \\
\hline & $(0.042)$ & $(1.223)$ & $(1.631)$ & $(0.013)$ & $(0.428)$ & $(0.501)$ \\
\hline R-squared & 0.000 & 0.016 & 0.213 & 0.000 & 0.026 & 0.107 \\
\hline \multicolumn{7}{|c|}{ D. Satisfaction with immediate manager } \\
\hline \multirow[t]{2}{*}{ Gay/Lesbian } & 0.076 & 0.089 & 0.111 & $0.059 * *$ & $0.061 * *$ & 0.049 \\
\hline & $(0.069)$ & $(0.071)$ & $(0.090)$ & $(0.027)$ & $(0.027)$ & $(0.035)$ \\
\hline \multirow[t]{2}{*}{ Constant } & $3.755 * * *$ & $6.676^{* * *}$ & $6.323 * * *$ & $0.311 * * *$ & $1.577 * * *$ & $1.475^{*}$ \\
\hline & $(0.051)$ & $(1.414)$ & $(1.987)$ & $(0.020)$ & $(0.584)$ & $(0.810)$ \\
\hline R-squared & 0.000 & 0.014 & 0.136 & 0.000 & 0.018 & 0.127 \\
\hline \multicolumn{7}{|c|}{ E. Satisfaction with nearest colleagues } \\
\hline \multirow[t]{2}{*}{ Gay males } & 0.010 & 0.026 & -0.003 & 0.037 & $0.050 *$ & 0.033 \\
\hline & $(0.044)$ & $(0.045)$ & $(0.058)$ & $(0.029)$ & $(0.029)$ & $(0.038)$ \\
\hline \multirow[t]{2}{*}{ Constant } & $4.314 * * *$ & $6.306^{* * *}$ & $6.554 * * *$ & $0.459 * * *$ & $1.872 * * *$ & $2.625^{* * * *}$ \\
\hline & $(0.032)$ & $(0.894)$ & $(1.291)$ & $(0.021)$ & $(0.602)$ & $(0.754)$ \\
\hline R-squared & 0.000 & 0.015 & 0.125 & 0.000 & 0.021 & 0.120 \\
\hline Observations & 1252 & 1252 & 1252 & 1252 & 1252 & 1252 \\
\hline Age and foreign born & No & Yes & Yes & No & Yes & Yes \\
\hline Demographic characteristics & No & No & Yes & No & No & Yes \\
\hline Health characteristics & No & No & Yes & No & No & Yes \\
\hline Job characteristics & No & No & Yes & No & No & Yes \\
\hline
\end{tabular}

The regressions are weighted and adjusted for sampling design using Stata svy commands. Demographic characteristics include controls for educational attainment and an indicator for living in a metropolitan area. Health characteristics include controls for general and mental health. Job characteristics include controls for annual labour earnings, number of weekly working hours, number of co-workers, business line, and an indicator for if the individual is employed in the public sector. The number of observations for the outcomes satisfaction with immediate boss and nearest colleagues is 1233 and 1246, respectively, due to that some do not have an immediate boss or immediate colleagues. Standard errors in parentheses. *** $p<0.01$, ** $p<0.05, * p<0.1$ 
in general and with various aspects of the job differ by sexual orientation. The estimates in column 2 , including controls for age and origin, are consistently positive, but the differences are not statistically significant. ${ }^{9}$

However, if the turn to the probability of being very satisfied with the job in columns 4-6, the results suggest that gay males are more likely to be very satisfied with the job, but also with the wage, promotion prospects, immediate manager, and nearest colleagues. In column 5, where we include the exogenous controls for age and origin, the estimated difference ranges from roughly 4 to 6 percentage points. However, when we add controls for demographic, health, and job characteristics - out of which some may be endogenous - in column 6 , the estimates become smaller and are no longer statistically significant. Thus, all in all the results suggest that gay males are more likely to be very satisfied with the different aspects of their job compared to heterosexual males. However, part of this differential may be explained by that gay males and heterosexuals have different demographic, health, and workplace characteristics.

Table 4 presents the corresponding estimation results for females. Columns 4-6 reveal only relatively small and statistically insignificant differences by sexual orientation in the probability of being very satisfied with different aspects of the job. However, the OLS estimates show that lesbians appear to have a lower satisfaction with the job in various dimensions. Columns 1 and 2 in panel A show that lesbians report a lower general job satisfaction than heterosexual females. However, the estimate is no longer statistically significant once we add the full set of controls in column 3 .

The estimates in columns $1-3$ in panel B indicate that lesbian women have a lower satisfaction with their wage than heterosexual women. However, the estimated difference is statistically significant only when we control for demographic, health, and job characteristics. Lesbian females are also less satisfied with their promotion prospects than heterosexual females (see columns $1-3$ in panel C). This pattern remains also when controls are added. As regards satisfaction with their immediate managers and nearest colleagues, the estimates suggest that lesbians are less satisfied than heterosexual females but the differences are not statistically significant (see columns 1-3 in panel $\mathrm{D}$ and $\mathrm{E})$.

To sum up, the estimates indicate that lesbian females are less satisfied with their job, generally but also with the wage and promotion prospects, than heterosexual females. As for males, part of this differential appear to be driven by that lesbians and heterosexual females may have different demographic, health, and workplace characteristics. However, there are no statistically significant differences in the probability of being very satisfied with various aspects of the job between lesbian and heterosexual females.

\section{Job Mentally Straining or Stressful}

Table 5 presents the linear probability estimates of reporting that the job is mentally straining or stressfull. Columns 1 and 2 in panel A show that gay men have an about 8 percentage points higher probability of reporting that their job is mentally straining than heterosexual men. However, when we add the full set of controls in column 3, the difference between gay men and heterosexual men is no longer statistically significant.

\footnotetext{
9 The full set of results are available from the authors upon request.
} 
Table 4 Linear probability and OLS estimates of different measures of job satisfaction, women

\begin{tabular}{|c|c|c|c|c|c|c|}
\hline & (1) & (2) & (3) & (4) & (5) & (6) \\
\hline Variables & OLS & OLS & OLS & LPM & LPM & LPM \\
\hline \multicolumn{7}{|l|}{ A. Job satisfaction } \\
\hline \multirow[t]{2}{*}{ Lesbian females } & $-0.095^{*}$ & $-0.131 * *$ & -0.053 & 0.031 & 0.011 & 0.026 \\
\hline & $(0.057)$ & $(0.062)$ & $(0.062)$ & $(0.026)$ & $(0.029)$ & $(0.028)$ \\
\hline \multirow[t]{2}{*}{ Constant } & $3.947 * * *$ & $4.268 * * *$ & $2.982 * * *$ & $0.273 * * *$ & 0.260 & 0.510 \\
\hline & $(0.037)$ & $(0.849)$ & $(1.012)$ & $(0.018)$ & $(0.446)$ & $(0.510)$ \\
\hline R-squared & 0.000 & 0.010 & 0.192 & 0.000 & 0.012 & 0.161 \\
\hline \multicolumn{7}{|l|}{ B. Satisfaction with wage } \\
\hline \multirow[t]{2}{*}{ Lesbian females } & -0.043 & -0.092 & $-0.142^{* *}$ & 0.010 & -0.003 & -0.024 \\
\hline & $(0.063)$ & $(0.069)$ & $(0.065)$ & $(0.019)$ & $(0.022)$ & $(0.022)$ \\
\hline \multirow[t]{2}{*}{ Constant } & $3.366^{* * * *}$ & $1.886^{*}$ & 1.816 & $0.121 * * *$ & -0.247 & 0.005 \\
\hline & $(0.044)$ & $(1.058)$ & (1.193) & $(0.013)$ & $(0.340)$ & $(0.372)$ \\
\hline R-squared & 0.000 & 0.014 & 0.173 & 0.000 & 0.010 & 0.130 \\
\hline \multicolumn{7}{|c|}{ C. Satisfaction with promotion prospects } \\
\hline \multirow[t]{2}{*}{ Lesbian females } & $-0.171^{* * * *}$ & $-0.241 * * *$ & $-0.235^{* * *}$ & 0.007 & -0.016 & -0.011 \\
\hline & $(0.060)$ & $(0.066)$ & $(0.066)$ & $(0.019)$ & $(0.023)$ & $(0.023)$ \\
\hline \multirow[t]{2}{*}{ Constant } & $3.345^{* * * *}$ & $4.382 * * *$ & $2.238^{*}$ & $0.128 * * *$ & 0.170 & 0.088 \\
\hline & $(0.040)$ & $(0.950)$ & $(1.252)$ & $(0.014)$ & $(0.324)$ & $(0.441)$ \\
\hline R-squared & 0.000 & 0.012 & 0.100 & 0.000 & 0.014 & 0.079 \\
\hline \multicolumn{7}{|c|}{ D. Satisfaction with immediate manager } \\
\hline \multirow[t]{2}{*}{ Lesbian females } & -0.022 & -0.078 & -0.088 & 0.024 & 0.014 & 0.004 \\
\hline & $(0.069)$ & $(0.074)$ & $(0.077)$ & $(0.027)$ & $(0.030)$ & $(0.031)$ \\
\hline \multirow[t]{2}{*}{ Constant } & $3.792 * * *$ & $3.507 * * *$ & $5.085^{* * * *}$ & $0.325 * * *$ & -0.248 & 0.623 \\
\hline & $(0.048)$ & $(1.026)$ & $(1.375)$ & $(0.019)$ & $(0.446)$ & $(0.557)$ \\
\hline R-squared & 0.000 & 0.008 & 0.085 & 0.000 & 0.007 & 0.092 \\
\hline \multicolumn{7}{|c|}{ E. Satisfaction with nearest colleagues } \\
\hline \multirow[t]{2}{*}{ Lesbian females } & 0.009 & -0.033 & -0.022 & 0.046 & 0.036 & 0.033 \\
\hline & $(0.047)$ & $(0.048)$ & $(0.051)$ & $(0.028)$ & $(0.031)$ & $(0.033)$ \\
\hline \multirow[t]{2}{*}{ Constant } & $4.332 * * *$ & $4.009 * * *$ & $4.613 * * *$ & $0.486^{* * *}$ & 0.136 & 0.839 \\
\hline & $(0.031)$ & $(0.710)$ & $(0.884)$ & $(0.020)$ & $(0.491)$ & $(0.605)$ \\
\hline R-squared & 0.000 & 0.015 & 0.139 & 0.000 & 0.015 & 0.148 \\
\hline Observations & 1252 & 1252 & 1252 & 1252 & 1252 & 1252 \\
\hline Age and foreign born & No & Yes & Yes & No & Yes & Yes \\
\hline Demographic characteristics & No & No & Yes & No & No & Yes \\
\hline Health characteristics & No & No & Yes & No & No & Yes \\
\hline Job characteristics & No & No & Yes & No & No & Yes \\
\hline
\end{tabular}

The regressions are weighted and adjusted for sampling design using Stata svy commands. Demographic characteristics include controls for educational attainment and an indicator for living in a metropolitan area. Health characteristics include controls for general and mental health. Job characteristics include controls for annual labour earnings, number of weekly working hours, number of co-workers, business line, and an indicator for if the individual is employed in the public sector. The number of observations for the outcomes satisfaction with immediate boss and nearest colleagues is 1230 and 1235 , respectively, due to that some do not have an immediate boss or immediate colleagues. Standard errors in parentheses. $* * * \mathrm{p}<0.01, * * \mathrm{p}<$ $0.05, * \mathrm{p}<0.1$ 
Table 5 Linear probability estimates of the probability of perceiving the job as mentally straining or stressful

\begin{tabular}{|c|c|c|c|c|c|c|}
\hline & (1) & (2) & (3) & (4) & (5) & (6) \\
\hline Variables & Men & Men & Men & Women & Women & Women \\
\hline \multicolumn{7}{|l|}{ A. Job mentally straining } \\
\hline \multirow[t]{2}{*}{ Gay/Lesbian } & $0.085^{* * *}$ & $0.082 * * *$ & 0.034 & $0.087 * * *$ & $0.080 * * *$ & $0.084 * * *$ \\
\hline & $(0.025)$ & $(0.026)$ & $(0.030)$ & $(0.024)$ & $(0.027)$ & $(0.027)$ \\
\hline \multirow[t]{2}{*}{ Constant } & $0.689 * * *$ & $-1.412^{* *}$ & $-1.703 * * *$ & $0.717 * * *$ & 0.560 & -0.300 \\
\hline & $(0.020)$ & $(0.577)$ & $(0.622)$ & $(0.018)$ & $(0.467)$ & $(0.580)$ \\
\hline R-squared & 0.000 & 0.034 & 0.158 & 0.000 & 0.029 & 0.152 \\
\hline \multicolumn{7}{|l|}{ B. Job stressful } \\
\hline \multirow[t]{2}{*}{ Gay/Lesbian } & $0.043 * *$ & $0.035^{*}$ & 0.025 & -0.006 & $-0.028 *$ & $-0.033 * *$ \\
\hline & $(0.018)$ & $(0.018)$ & $(0.024)$ & $(0.016)$ & $(0.015)$ & $(0.016)$ \\
\hline \multirow[t]{2}{*}{ Constant } & $0.864 * * *$ & 0.077 & -0.182 & $0.919 * * *$ & $1.249 * * *$ & $0.743^{* *}$ \\
\hline & $(0.015)$ & $(0.407)$ & $(0.520)$ & $(0.011)$ & $(0.210)$ & $(0.338)$ \\
\hline R-squared & 0.000 & 0.033 & 0.081 & 0.000 & 0.021 & 0.101 \\
\hline Observations & 1252 & 1252 & 1252 & 1241 & 1241 & 1241 \\
\hline Age and foreign born & No & Yes & Yes & No & Yes & Yes \\
\hline Demographic characteristics & No & No & Yes & No & No & Yes \\
\hline Health characteristics & No & No & Yes & No & No & Yes \\
\hline Job characteristics & No & No & Yes & No & No & Yes \\
\hline
\end{tabular}

The regressions are weighted and adjusted for sampling design using Stata svy commands. Demographic characteristics include controls for educational attainment and an indicator for living in a metropolitan area. Health characteristics include controls for general and mental health. Job characteristics include controls for annual labour earnings, number of weekly working hours, number of co-workers, business line, and an indicator for if the individual is employed in the public sector. Standard errors in parentheses. $* * * \mathrm{p}<0.01$, ** $\mathrm{p}<0.05, * \mathrm{p}<0.1$

Among females, lesbians have a statistically significant higher probability of reporting that their job is mentally straining than heterosexual females do, in all specifications. The difference amounts to between 8 and 9 percentage points.

Column 1 in panel B in Table 5 reveals that gay men have a statistically significant higher probability than heterosexual men of reporting that their job is stressful. This differential is robust to adding controls for age and origin (see column 2). However, when we control for demographic, health, and job characteristics in column 3 there is no statistically significant difference between gay men and heterosexual men. In contrast, column 4 in Table 5 shows that there is no difference by sexual orientation in the probability of perceiving the job as stressful among women. However, when we add the exogeneous controls (age and origin) and the full set of controls in columns 5 and 6, respectively, lesbian females are around 3 percentage points less likely to perceive the job stressful than heterosexual females.

\section{Omitted Variable Bias}

To estimate the causal effect of sexual orientation on job sastifaction we would ideally like to compare individuals who have the same level of producitivity and the same 
workplace charachteristics and only differ in their sexual orientation. In the empirical analysis we used various observable variables to control for such differences. However, it may be the case that the control variables included in the analysis do not fully capture and are incomplete proxies of worker productivity and workplace charactersitics. To address this potential problem and to test the robustness of our results to omitted variable bias, we use the strategy proposed by Oster (2019).

Oster's test of omitted variable bias involves computing bounding values for the treatment effect, which in this case is being gay male or lesbian. To compute the bounding values one uses information on both the coefficient and R-squared movements that arise when additional controls are added to the regression. The bounding values comprise 1 ) the estimated controlled coefficient from a controlled model, $\widetilde{\beta}$, and 2) a bias-adjusted coefficient, $\beta^{*}$.

$\widetilde{\beta}$ is the estimated coefficient for the treatment from a model that includes the observed control variables. $\beta^{*}$ is a coefficient for the treatment that comes from a hypothetical estimated model that includes controls for both observable and unobservable variables. $\beta^{*}$ can be calculated using the following formula:

$$
\beta^{*} \approx \widetilde{\beta}-\delta[\dot{\beta}-\widetilde{\beta}] \frac{R_{\max }-\widetilde{R}}{\widetilde{R}-\dot{R}}
$$

where $\dot{\beta}$ and $\dot{R}$ are the coefficient and R-squared, respectively, from a regression with the treatment only, and $\widetilde{\beta}$ and $\widetilde{R}$ are the coefficient and R-squared, respectively, from a regression with the treatment and the observed controls. $\delta$ is the coefficient of proportionality and measures the of the correlation between unobservable characteristics and the treatment relative to the observable characteristics. $R_{\max }$ is the overall R-squared of the hypothetical model controlling for both observables and unobservables. As proposed by Oster (2019) we assume that $\delta$ is equal to 1, i.e. that unobservable factors are as important as observable factors in explaining the outcome variable, and that $R_{\max }=1.3 \widetilde{R}$, where $\widetilde{R}$ is the R-squared value from the regression model including the treatment and the observed controls.

Oster (2019) argues that estimated treatment from the controlled regression can be considered as robust to omitted variable bias if the identified set, $\left[\widetilde{\beta}, \beta^{*}\right]$, excludes zero. In addition, if the estimated coefficient does not move towards zero once observed controls are added, Oster (2019) also recommends investigating whether the bounds of the identified set are within the confidence interval of $\widetilde{\beta}$. If this is the case, the estimate is considered as robust.

Oster (2019) further suggests calculating the value of $\delta$ that produces a zero treatment effect with $R_{\max }=1.3 \widetilde{R}$. In this case, values of $\delta>1$ indicate a robust result, since the unobserverables then would have to be more important than the observed variables to produce a zero effect.

Tables 8 and 9 in Appendix A show the results from the robustness test for men and women, respectively. We have performed the test using both specification (2) and (3). Column (1) shows the estimated coefficient and R-squared from the model with the treatment only, i.e. $\dot{\beta}$ and $\dot{R}$, and column (2) presents the estimated coefficient from the model with the treatment and observable controls, i.e. $\widetilde{\beta}$ and $\widetilde{R}$. Column (3) shows the 
identified set for the treatment effect and column (4) indicates whether the identified set excludes zero. Column (5) reports whether the bias-adjusted coefficient, $\beta^{*}$, lies within the confidence interval of the estimated controlled effect and, finally, column (6) presents the $\delta$-value needed to produce a zero treatment effect.

Generally, Tables 8 and 9 suggest that the estimated results, with few exceptions, are robust to omitted variables bias, both for men and women. In most cases Tables 8 and 9 reveal that the identified set excludes zero, that the bounding values of the treatment are within the confidence interval of $\widetilde{\beta}$, and that the $\delta$ needed to produce a zero treatment effect is larger than one.

\section{Heterogeneity Analysis}

Previous research indicates that gay males and lesbian females have worse labour market outcomes than heterosexuals in the private sector and in non-metropolitan areas, suggesting that job satisfaction may also vary across these dimensions (e.g., Ahmed and Hammarstedt 2010; Ahmed et al. 2013a). When it comes to education, empirical evidence shows that job satisfaction is positively related to educational attainment; more education enables individuals to find jobs with charachteristics that give a higher level of satisfaction (Fabra and Camisón 2009). Further, previous research also documents a link between a low job satisfication and large firm size (Scherer 1976; Clark 1996). To explore wehther job satisfaction by sexual orientation differs by sector of employment, educational attainment, area of residence, and number of employees in the workplace we have estimated equation 1 and 2 including an interaction between sexual orientation and the variable at hand. We do not present any estimates - available upon request - but we comment on the main results.

Starting with men the results reveal very few differences by sector of employment, educational attainment, area of residence, and number of employees at the workplace. There is some evidence that gay males are less satisfied with their immediate boss than heterosexual males if they have less than university education and live in metropolitan areas. Among the low educated, gay males are also more likely to perceive their job as mentally strainig or stressful than heterosexual men, while there are no such differences for men with a university degree.

Among women, the results suggest that lesbian women who work in the private sector are more likely to be very satisfied with their job - in general and in terms of promotion prospects - than heterosexual women. We observe the opposite pattern among women in the public sector. The results also indicate that women with primary or secondary education are less likely to be satisfied with their job - in general and with the immediate manager - than heterosexual women. Among women with a university degree there are no such differences. Finally, we find that being employed in a workplace with less than ten employees appears to be associated with a lower job satisfaction among lesbian women than among heterosexual women, both in terms of satisfaction with their immediate boss and with promotion prospects.

\section{Discussion and Conclusions}

We present results from a survey on sexual orientation and job satisfaction conducted in Sweden. Our study is unique because it is nationwide and because we use a broad range 
of measures to explore how job satisfaction varies with sexual orientation. It is worth noting that the results in our study are based on a larger sample than the results in previous research.

Results from previous research in this area in most cases indicates that both gay men and lesbians are less satisfied with their job than heterosexuals are. One striking difference between the results in our study and previous results is that gay men are more often very satisfied with their job and different aspects of the job than heterosexual men. In contrast, for lesbians we find - more in line with previous studies - lower levels of satisfaction with various aspects of the job compared to heterosexual women. Thus, our study reveals a considerable gender difference in job satisfaction.

That job satisfaction and sexual orientation is a complex question is also underlined by the fact that both gay men and lesbians to a larger extent than heterosexuals find their job mentally straining. Thus, even though gay males are more likely to be very satisfied with their job, they are also facing other straining circumstances than heterosexuals in their working life.

So what can we learn from these results? Previous research has shown that gay men are at a disadvantage on the labour market compared to heterosexual men. Gay men earn less, are discriminated against in hiring and are under-represented in managerial positions compared to heterosexual males (e.g., Ahmed and Hammarstedt 2010; Ahmed et al. 2011a, b, 2013a, b). Still, our results indicate that they are more likely to be very satisfied with their job and various aspects of the jobthan heterosexual males. For lesbians, the labour market situation is different. They earn about the same as heterosexual females and they are over-represented in managerial positions compared to heterosexual females. Nonetheless, they are less satisfied with their job and with their chances of promotion.

How can we explain these results? Maybe we have to turn our attention to the individuals' expectations of their working life. The existence of discrimination and sexual prejudice may lead to gay men having lower expectations of wages, promotion possibilities and treatment from managers and colleagues than heterosexual men. These low expectations may transform into greater job satisfaction among gay men, given that they perceive that have reached a better position than expected. A similar explanation has been used to explain that females, despite lower earnings and promotion prospects, report higher job satisfaction than males (Clark 1997; Sousa-Poza and Souza-Posa 2003; Gazioglu and Tansel 2006).

Turning to lesbians, they are less likely than heterosexual females to have children (e.g., Aldén et al. 2015). The literature has also posited that lesbians are more careeroriented than heterosexual females (Peplau and Fingerhut 2004). If so, this may lead to them having higher expectations of their job, their wages and on their promotion prospects. If prejudice and discrimination keep lesbians from reaching their expectations, this may result in diminished job satisfaction compared to heterosexual women. It may also be that lesbian females, as women in general, suffer from statistical discrimination based on their gender. However, there may be reason to suspect that this result is driven by sample selection bias. The finding that women have a higher job satisfaction than men is typically based on a comparison of married women and married men (Clark 1997; Souza-Poza and Souza-Poza 2003; Gazioglu and Tansel 2006). Carleton and Clain (2012) argue that married women who are active on the labour market, due to 
traditional gender roles, are likely to be selected in terms of a taste for market and an expectation of high level of job satisfaction. Men's decision to work, on the other hand, is less likely to be affected by these factors. As a result, women who are not satisfied with their job may be more prone to quit their job to find something better whereas men tend to stay at an unsatisfying job. Indeed, Carleton and Clain (2012) find that sample selection related to the decision to work explain the higher job satisfaction of married women. If the heterosexual women in our sample are selected in a similar way while lesbian women are not, this could explain the lower job satisfaction of lesbian women. However, Green et al. (2016) show that the female job satisfaction gap, documented by Clark (1997) in the UK, has more or less disappeared over time, largely driven by a less favourable evaluation of job characteristics as more women have entered the labour market. This indicates that married women in more recent cohort are less likely to be a selected sample. In addition, in Sweden the employment rate and labour force participation rate of married women is high. Further, the test of omitted variable bias demonstrated that the results appear to be robust to such bias. All in all, this suggests that sample selection may not be a (severe) problem in this case.

Irrespective of the explanation behind the results, we can conclude that sexual orientation matters not only hiring, but also at the workplace. Thus, one policy implication is that measures to prevent discrimination in hiring is not enough to create an equal working life for homosexuals and heterosexuals. The fact that gay men and lesbians perceive their job as mentally straining to a larger extent than heterosexuals, and that lesibans are less satisfied with their job and promotion prospects than heterosexual females, underline that different measures to create an equal working life irrespective of sexual orientation are needed.

To sum up, our results have shown that in addition to the observed earnings differentials due to sexual orientation and discrimination in hiring, there are also differences in job satisfaction due to sexual orientation. The explanations behind this result deserve additional attention. So does the fact that our results are based on individuals who are married and therefore not necessarily representative for single and cohabitating individuals. The results from our survey add one additional part to the puzzle on sexual orientation and labour market outcomes, but at the same time they underline the fact that more research in this area is needed.

Acknowledgements We thank Lee Badgett, seminar participants at Linnaeus University and at Centre d'Economie de la Sorbonne as well as participants at the annual meeting of Society of the Economics of the Households in Paris 2018 for useful comments and discussions. We also thank the editor and the anonymous referees for useful suggestions.

Data Availability Statement The datasets generated during and/or analysed during the current study are not publicly available due to a confidentiality agreement with Statistics Sweden stating that the data can only be used in this project and by researchers active in the project. However, the data are available from upon reasonable request and with permission of Statistics Sweden.

Funding Information Open access funding provided by Linnaeus University.

\section{Compliance with Ethical Standards}

Conflict of Interest The authors declare that they have no conflict of interest. 


\section{Appendix}

Table 6 Descriptive statistics of respondents, non-respondents, total sample, and total population

\begin{tabular}{lllll}
\hline & Respondents & Non-respondents & Total sample & Total population \\
\hline Female & 50.1 & 50.2 & 50.2 & 52.6 \\
Age & & & & \\
$25-29$ & 2.2 & 3.8 & 2.9 & 3.8 \\
$30-34$ & 6.0 & 11.9 & 8.7 & 9.1 \\
$35-39$ & 13.0 & 17.4 & 15.0 & 12.9 \\
$40-44$ & 15.2 & 20.9 & 17.7 & 15.7 \\
$45-49$ & 16.3 & 16.3 & 16.3 & 16.0 \\
$50-54$ & 17.4 & 13.7 & 15.7 & 16.0 \\
$55-59$ & 15.7 & 9.2 & 12.8 & 13.9 \\
$60-64$ & 14.0 & 6.8 & 10.8 & 13.0 \\
Foreign born & 15.7 & 22.9 & 18.9 & 19.0 \\
Annual labour earnings & $(S E K)$ & & & \\
$0-124,999$ & 2.1 & 6.9 & 4.2 & 7.6 \\
$125,000-199,999$ & 4.0 & 8.1 & 5.9 & 6.4 \\
$200,000-279,999$ & 14.3 & 17.0 & 15.5 & 12.9 \\
$280,000-369,999$ & 29.6 & 29.6 & 29.6 & 25.5 \\
$370,000-$ & 50.0 & 38.3 & 44.8 & 47.6 \\
Metropolitan area & 30.4 & 28.4 & 29.5 & 35.1 \\
Observations & 2648 & 2135 & 4783 & $1,636,484$ \\
\hline S & & & &
\end{tabular}

Statistics Sweden has produced and provided us with the statistics for the respondents and the total sample. Using register data from Statistics Sweden we have produced the corresponding descriptive statistics for the underlying population from which the sample was randomly drawn 
Table 7 Descriptive statistics of the total population

\begin{tabular}{|c|c|c|c|c|}
\hline & $\begin{array}{l}\text { Heterosexual } \\
\text { males }\end{array}$ & Gay males & $\begin{array}{l}\text { Heterosexual } \\
\text { females }\end{array}$ & $\begin{array}{l}\text { Lesbian } \\
\text { females }\end{array}$ \\
\hline Age & 47.3 & $46.1 * * *$ & 46.8 & $41.0 * * *$ \\
\hline \multicolumn{5}{|l|}{ Education } \\
\hline Primary school & 0.103 & $0.053 * * *$ & 0.060 & $0.033 * * *$ \\
\hline Secondary school & 0.452 & $0.336 * * *$ & 0.394 & $0.298 * * *$ \\
\hline University & 0.445 & $0.611 * * *$ & 0.546 & $0.669 * * *$ \\
\hline Born outside Sweden & 0.192 & $0.207^{* *}$ & 0.184 & $0.134 * * *$ \\
\hline Metropolitan area & 0.352 & $0.612 * * *$ & 0.346 & $0.464 * * *$ \\
\hline Annual earnings, SEK & 472,000 & $461,500 * *$ & 336,200 & $342,100^{* *}$ \\
\hline \multicolumn{5}{|l|}{ Business line } \\
\hline Manufacturing & 0.203 & $0.042 * * *$ & 0.063 & $0.053 * * *$ \\
\hline Construction & 0.096 & $0.012 * * *$ & 0.013 & $0.016^{* *}$ \\
\hline Trade & 0.121 & $0.102 * * *$ & 0.088 & $0.069^{* * * *}$ \\
\hline Information and communication & 0.064 & $0.060 * * *$ & 0.025 & 0.039 \\
\hline Transport and warehousing & 0.070 & $0.057 * * *$ & 0.018 & $0.034 * * *$ \\
\hline $\begin{array}{l}\text { Finance, insurance, business } \\
\text { services }\end{array}$ & 0.093 & 0.102 & 0.082 & $0.075^{*}$ \\
\hline Public administration & 0.062 & 0.059 & 0.044 & 0.047 \\
\hline Law, business, and technology & 0.069 & $0.101 * * *$ & 0.086 & $0.118 * * *$ \\
\hline Education & 0.067 & $0.111 * * *$ & 0.208 & $0.180^{* * * *}$ \\
\hline Health care and social services & 0.068 & $0.205 * * *$ & 0.298 & $0.267 * * *$ \\
\hline Services & 0.018 & $0.045^{* * * *}$ & 0.025 & $0.037 * * *$ \\
\hline Other & 0.069 & $0.103 * * *$ & 0.049 & $0.063 * * *$ \\
\hline Public sector & 24.2 & $41.1 * * *$ & 53.9 & 53.0 \\
\hline Observations & 770,706 & 3001 & 857,837 & 4940 \\
\hline
\end{tabular}

Using register data from Statistics Sweden we have produced descriptive statistics for the underlying population from which the sample was randomly drawn. The table presents the control variables included in the analysis that we were able to construct using the register data. $* * *, * *$, and * indicate statistical significance of difference by sexual orientation within gender at the 1-, 5-, and $10 \%$ level 


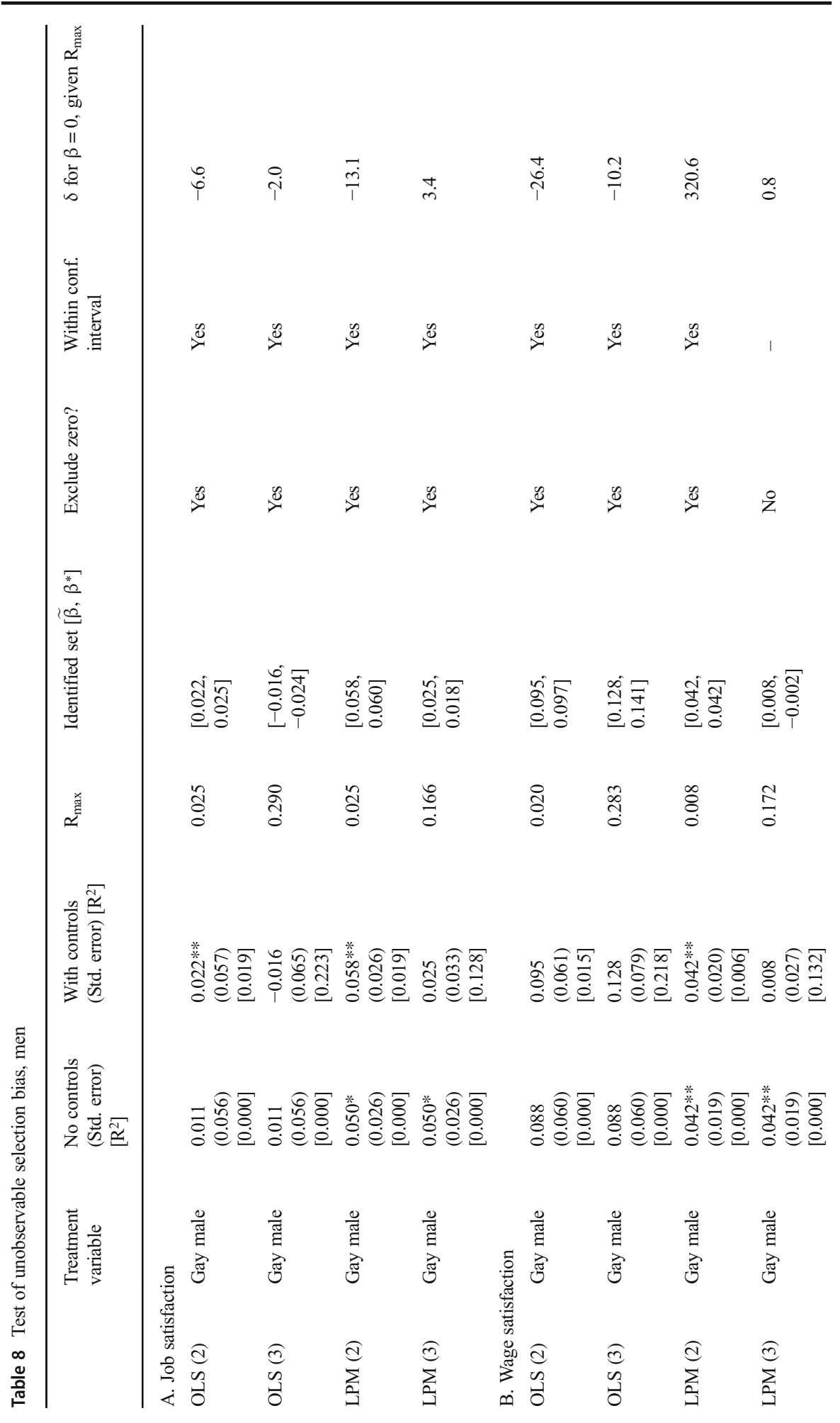




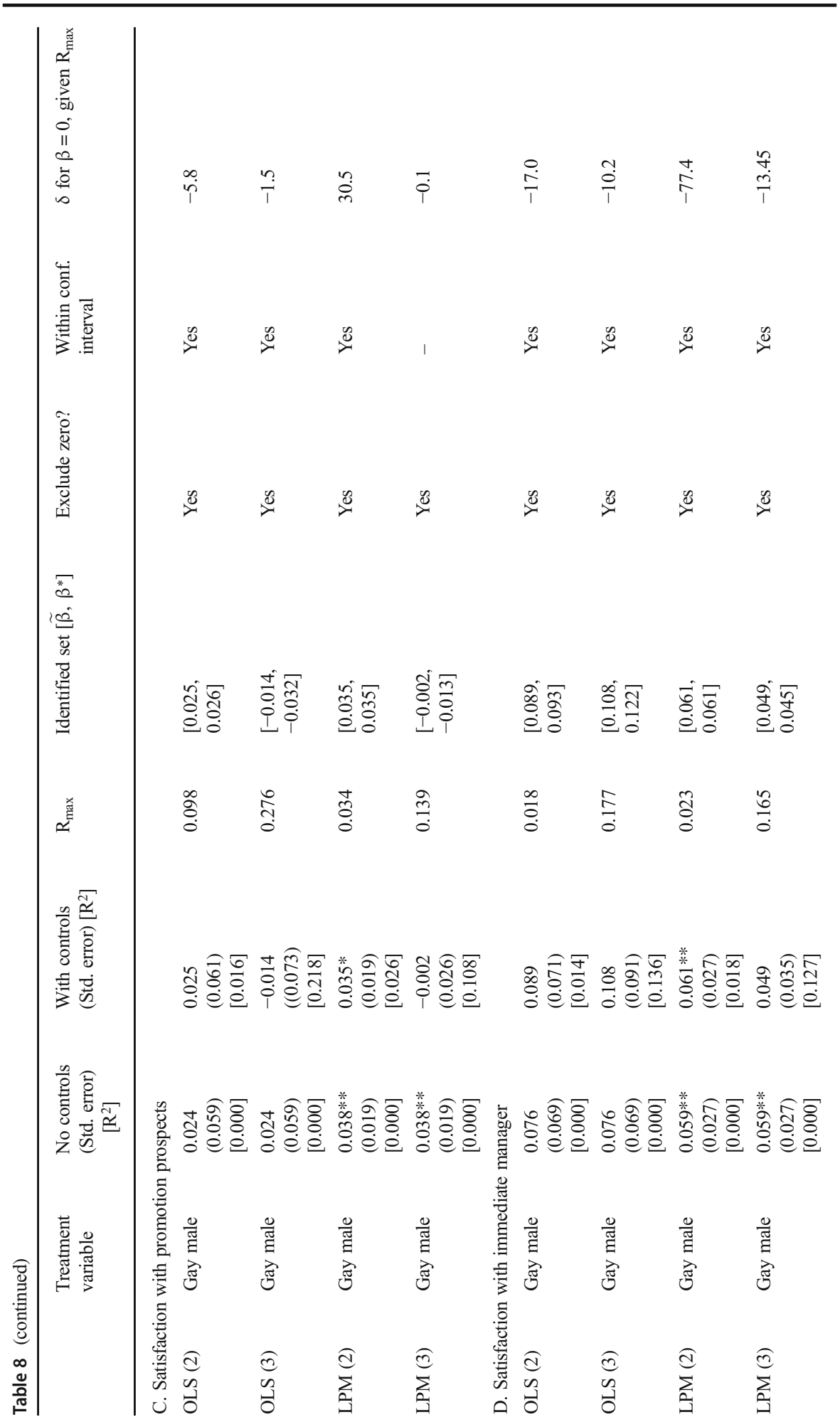




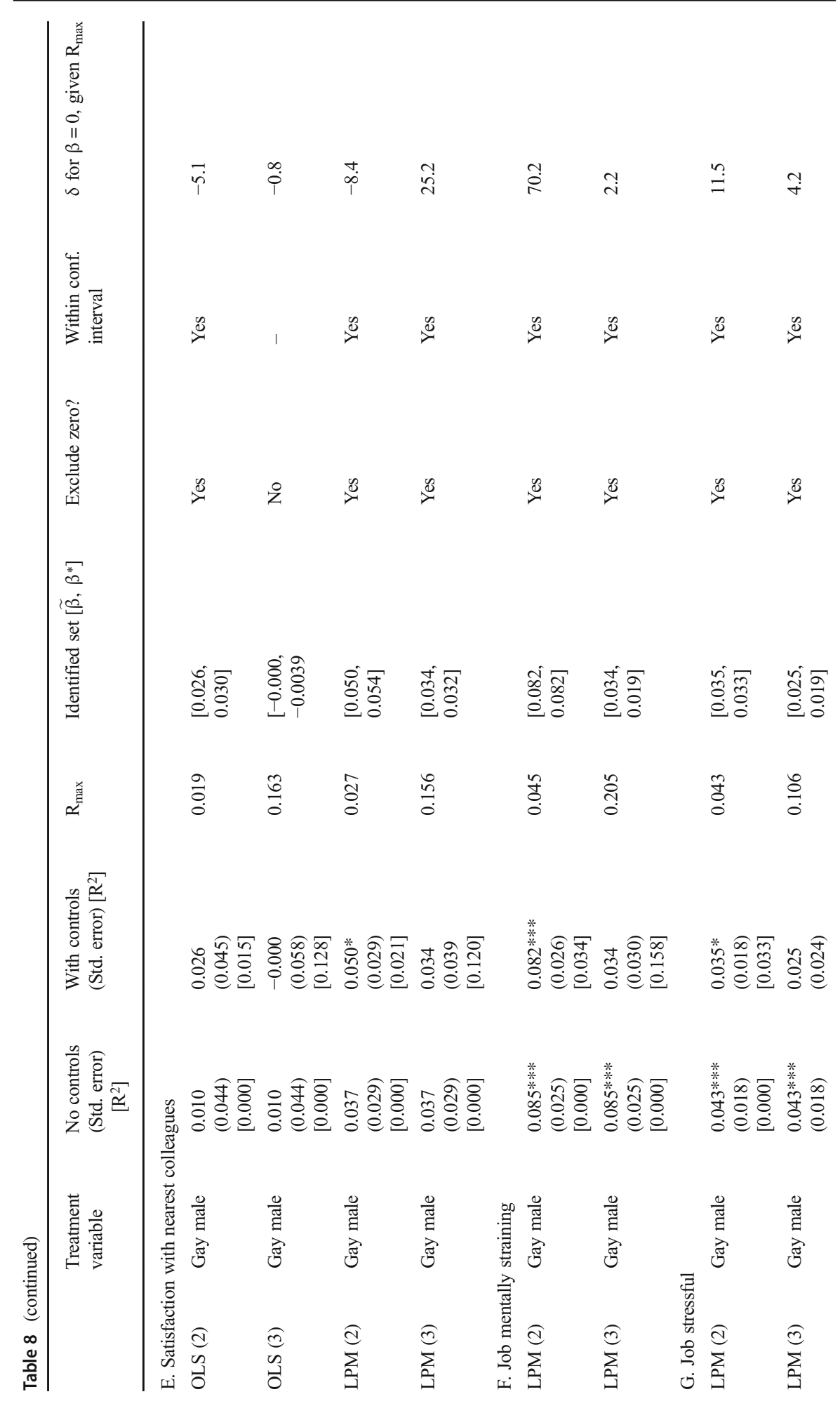




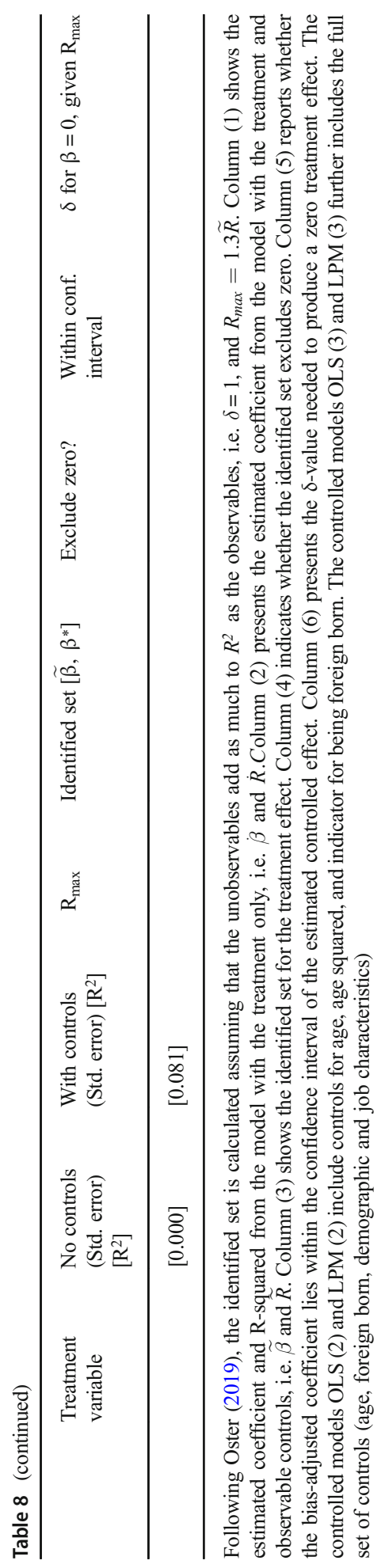




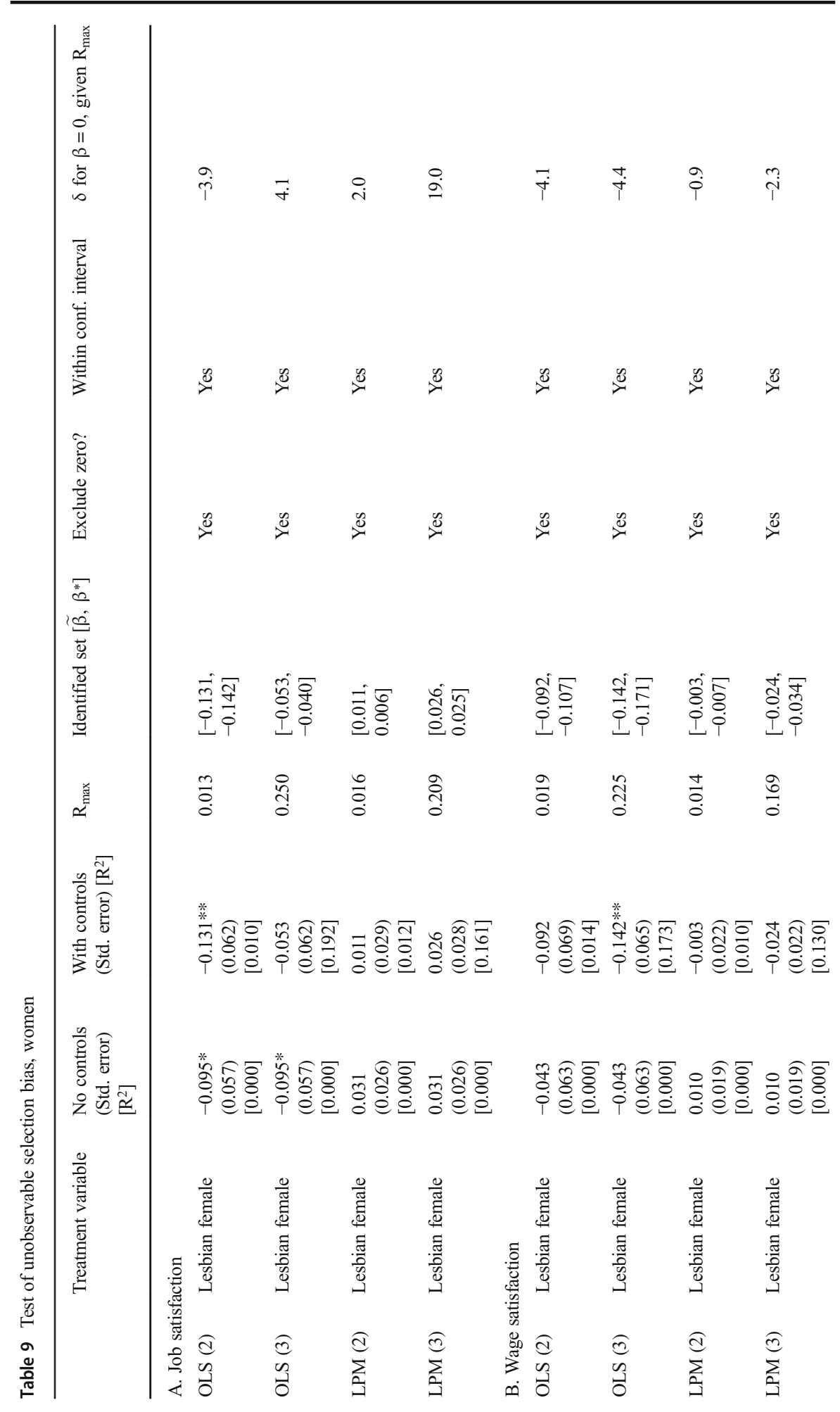




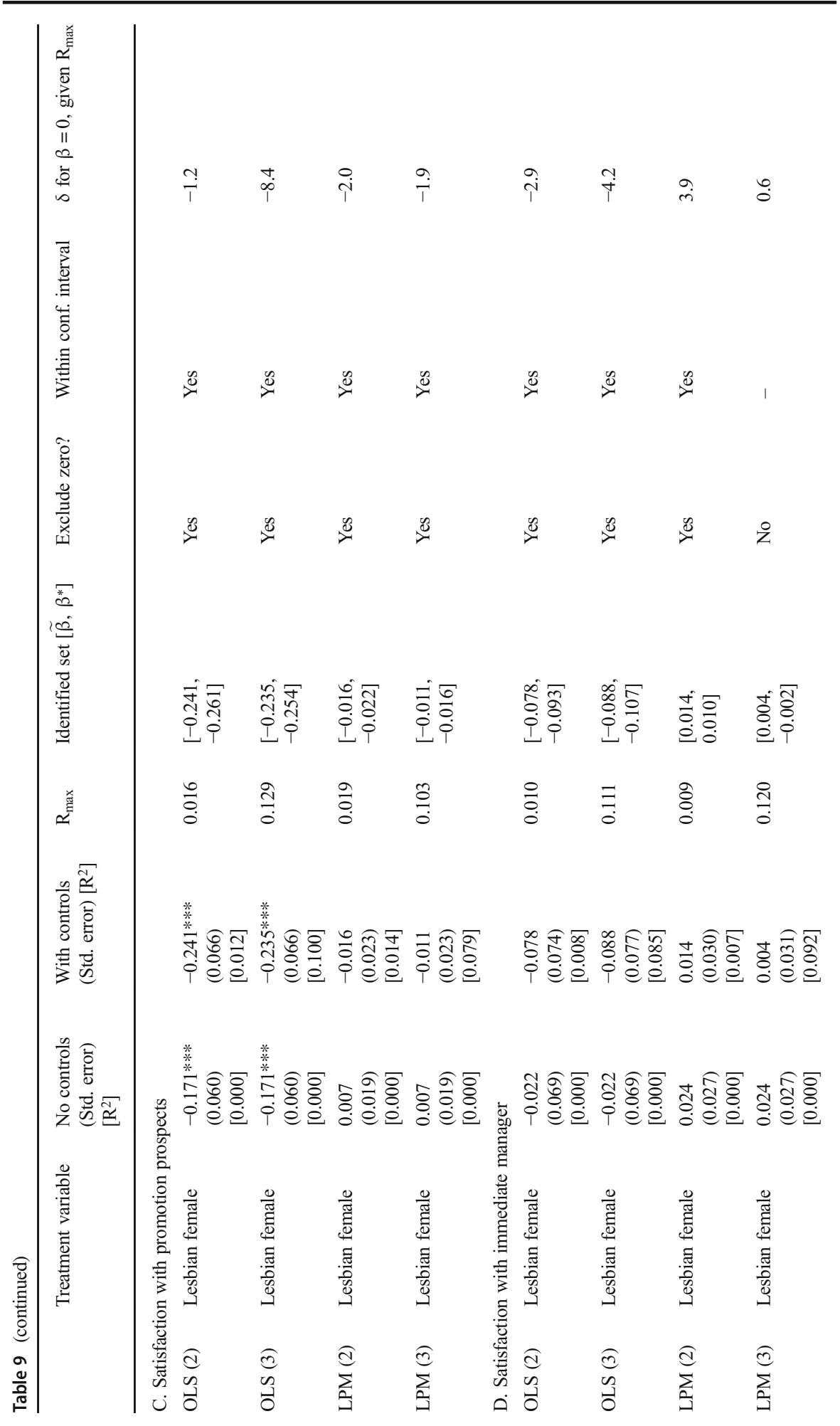




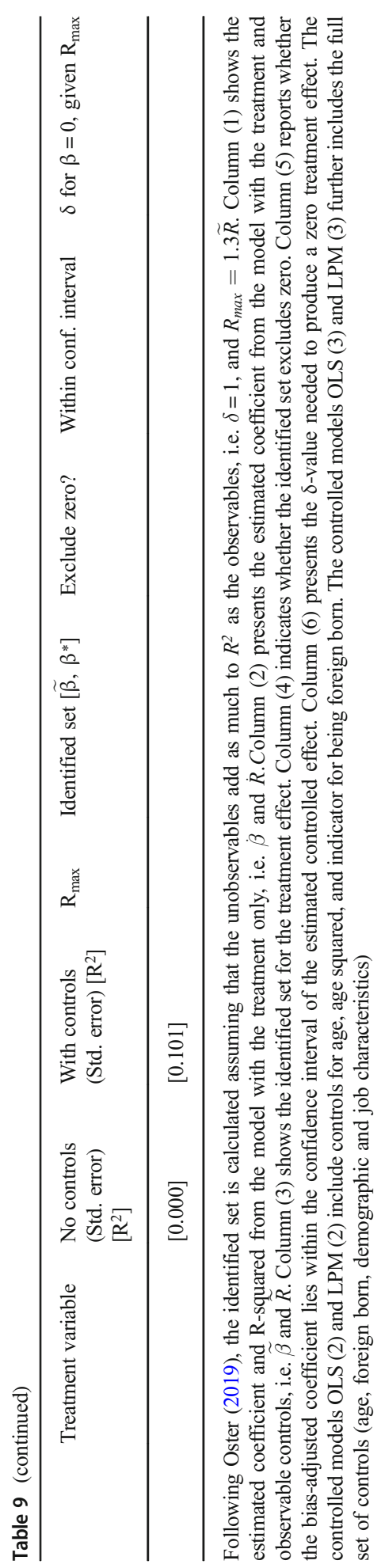


Open Access This article is licensed under a Creative Commons Attribution 4.0 International License, which permits use, sharing, adaptation, distribution and reproduction in any medium or format, as long as you give appropriate credit to the original author(s) and the source, provide a link to the Creative Commons licence, and indicate if changes were made. The images or other third party material in this article are included in the article's Creative Commons licence, unless indicated otherwise in a credit line to the material. If material is not included in the article's Creative Commons licence and your intended use is not permitted by statutory regulation or exceeds the permitted use, you will need to obtain permission directly from the copyright holder. To view a copy of this licence, visit http://creativecommons.org/licenses/by/4.0/.

\section{References}

Adam BD (1981) Stigma and employability: discrimination by sex and sexual orientation in the Ontario legal profession. Canadian Review of Sociology and Anthropology 18(2):216-221

Ahmad S, Bhugra D (2010) Homophobia: an updated review of the literature. Sex Relatsh Ther 25(4):447455

Ahmed A, Hammarstedt M (2010) Sexual orientation and earnings: a register data based approach to identify homosexuals. J Popul Econ 23(3):835-849

Ahmed A, Andersson L, Hammarstedt M (2011a) Inter- and intra-household earnings differentials among homosexual and heterosexual couples. Br J Ind Relat 49(s2):s258-s278

Ahmed A, Andersson L, Hammarstedt M (2011b) Sexual orientation and occupational rank. Econ Bull 31(3): 2422-2433

Ahmed A, Andersson L, Hammarstedt M (2013a) Are gay men and lesbians discriminated against in the hiring process? South Econ J 79(3):565-585

Ahmed A, Andersson L, Hammarstedt M (2013b) Sexual orientation and full-time monthly earnings, by public and private sector: evidence from Swedish register data. Rev Econ Househ 11(1):83-108

Aldén L, Edlund L, Hammarsetdt M, Mueller-Smith M (2015) Effect of registered partnership on labor earnings and fertility for same-sex couples: evidence from Swedish register data. Demography 52(4): 1243-1268

Allegretto SA, Arthur MM (2001) An empirical analysis of homosexual/heterosexual male earnings differentials: unmarried or unequal? Ind Labor Relat Rev 54(3):631-646

Arabsheibani GR, Marin A, Wadsworth J (2004) In the pink: homosexual-heterosexual wage differentials in the UK. Int J Manpow 25(3/4):343-354

Arabsheibani GR, Marin A, Wadsworth J (2005) Gay pay in the UK. Economica 72(286):333-347

Badgett MVL (1995) The wage effects of sexual orientation discrimination. Ind Labor Relat Rev 48(4):726739

Badgett MVL (2001) Money, myths, and change: the economic lives of lesbians and gay men. University of Chicago Press, Chicago

Badgett MVL, Lau H, Sears B, Ho D (2007) Bias in the workplace: consistent evidence of sexual orientation and gender identity discrimination. Williams Institute, UCLA School of Law, University of California, Los Angeles, CA

Baert S (2014) Career lesbians. Getting hired for not having kids? Ind Relat 45(6):543-561

Bender KA, Donohue SM, Heywood JS (2005) Job satisfaction and gender segregation. Oxf Econ Pap 59(2): 275-300

Bhugra D (1987) Homophobia: a review of the literature. Sexual and Marital Therapy 2(2):169-177

Bränström R (2017) Minority stress factors as mediators of sexual orientation disparities in mental health treatment: a longitudinal population-based study. Journal of Epidemiol Community Health 71:446-452

Carleton CJ, Clain SH (2012) Women, men, and job satisfaction. East Econ J 38(3):331-355

Carpenter CS (2005) Self-reported sexual orientation and earnings: evidence from California. Ind Labor Relat Rev 58(2):258-273

Carpenter CS (2008a) Sexual orientation, work, and income in Canada. Can J Econ 41(4):1239-1261

Carpenter CS (2008b) Sexual orientation, income, and non-pecuniary economic outcomes: new evidence from young lesbians in Australia. Rev Econ Househ 6(4):391-408

Chakraborty A, McManus S, Brugha TS, Bebbington P, King M (2011) Mental health of the non-heterosexual population of England. Brtitish Journal of Psychiatry 198(2):143-148 
Clain SH, Leppel K (2001) An investigation into sexual orientation discrimination as an explanation for wage differences. Appl Econ 33(1):37-47

Clark AE (1996) Job satisfaction in Britain. Br J Ind Relat 34(2):189-217

Clark AE (1997) Job satisfaction and gender: why are women so happy at work? Labour Econ 4(4):341-372

Deardorff AV, Stafford FP (1976) Compensation of cooperating factors. Econometrica 44(4):671-684

Dilmaghani M (2018) Sexual orientation, labour supply, and occupational sorting in Canada. Ind Relat 49(4): 298-318

Drago R, Wooden M (1992) The determinants of labor absence: economic factors and workgroup norms across countries. Industrial and Labor Relations Review 45(4):341-372

Drydakis N (2009) Sexual orientation discrimination in the labour market. Labour Econ 16(4):364-372

Drydakis N (2011) Women's sexual orientation and labour market outcomes in Greece. Fem Econ 17(1):89117

Drydakis N (2012) Men's sexual orientation and job satisfaction. Int J Manpow 33(8):901-917

Drydakis N (2015) Effects of sexual orientation on job satisfaction: evidence from Greece. Ind Relat 54(1): $162-187$

European Union Agency for Fundamental Rights (2013) EU LGBT survey: European Union lesbian. Results at a glance. Vienna, Gay, Bisexual Transgender Survey

Fabra EM, Camisón C (2009) Direct and indirect effects of education on job satisfaction: a structural model for the Spanish case. Econ Educ Rev 28(5):600-610

Ferrer-i-Crabonell A, Frijters P (2004) How important is methodology for the estimates of the determinants of happiness? Economic Journal 114(497):641-659

Freeman RB (1978) Job satisfaction as an economic variable. Am Econ Rev 68(2):135-141

Gazioglu S, Tansel A (2006) Job satisfaction in Britain: individual and job-related factors. Appl Econ 38(10): 1163-1171

Green F (2010) Well-being, job satisfaction, and labour mobility. Labour Econ 17(6):897-903

Green CP, Heywood JS (2011) Flexible contracts and subjective well-being. Econ Inq 49(3):716-729

Green CP, Heywood JS, Kler P, Leeves G (2016) Paradox lost: the disappearing female job satisfaction premium. Br J Ind Relat 56(3):484-502

Hammarstedt M, Ahmed A, Andersson L (2015) Sexual prejudice and labor market outcomes of gays and lesbians: evidence from Sweden. Fem Econ 21(1):90-109

Hebl MR, Bigazzi Foster J, Mannix LM, Dovidio JF (2002) Formal and interpersonal discrimination: a field study of Bias towards homosexual applicants. Personal Soc Psychol Bull 28(6):815-825

Herek GM (2002) Gender gaps and public opinion about lesbians and gay men. Public Opinion Quarterly 66(1):40-66

Heywood JS, Siebert WS, Wei X (2007) The implicit wage costs of family friendly work practices. Oxf Econ Pap 59(2):275-300

Judge TA, Thoresen CJ, Bono JE, Patton GK (2001) The job satisfaction-job performance relationship: a qualitative and quantitative review. Psychol Bull 127(3):376-407

Kite ME, Whitley BE (1996) Sex differences in attitudes toward homosexual persons, behaviors, and civil rights: a meta-analysis. Personal Soc Psychol Bull 22(4):336-353

Klawitter M (2011) Multilevel analysis of the effects of antidiscrimination policies and earnings by sexual orientation. Journal of Policy Analysis and Management 30(2):334-358

Klawitter MM, Flatt V (1998) The effects of state and local antidiscrimination policies for gays and lesbians. Journal of Policy Analysis and Management 17(4):658-686

Leppel K (2014) Does job satisfaction vary with sexual orientation? Ind Relat 53(2):169-198

Leppel K, Clain SH (2015) Exploring job satisfaction by sexual orientation, gender, and marital status. East Econ J 41(4):547-570

Locke EA (1976) The nature and causes of job satisfaction. In: Dunnette MD (ed) Handbook of industrial and Organisational psychology. Rand and McNally, Chicago, pp 1297-1349

Locke EA (1984) Job satisfaction. In: Gruneberg M, Wall T (eds) Social psychology and organizational behaviour. John Willey and Sons, London

Martell ME (2014) How ENDAs extend the workweek: legal protection and the labor supply of behaviorally gay men. Contemp Econ Policy 32(3):560-577

Martell ME, Roncolato L (2016) The homosexual lifestyle: time use in same-sex households. Journal of Dempographic Economics 82(4):365-398

McFarlin DB, Coster EA, Rise RW, Cooper AT (1995) Facet importance and job satisfaction: another look at range-of-affect hypothesis. Basic Appl Soc Psychol 16(4):489-502

Meyer IH (2003) Prejudice, social stress, and mental health in lesbian, gay, and bisexual populations: conceptual issues and research evidence. Psychol Bull 129(5):674-697 
Oster E (2019) Unobservable selection and Coeffiencet stability: theory and evidence. J Bus Econ Stat 37(2): 187-204

Patterson M, Warr P, West M (2004) Organizational climate and company productivity: the role of employee affect and employee level. J Occup Organ Psychol 77(2):193-216

Peplau LA, Fingerhut A (2004) The paradox of the lesbian worker. J Soc Issues 60(4):719-735

Plug E, Berkhout P (2004) Effects of sexual preferences on earnings in the Netherlands. J Popul Econ 17(1): $117-131$

Plug E, Webbink D, Martin N (2014) Sexual orientation, prejudice, and segregation. J Labor Econ 32(1):123159

Saltzstein AL, Ting Y, Saltzstein GH (2011) Work-family balance and job satisfaction: the impact of familyFriendy policies of attitudes of Federal Government Employees. Public Adm Rev 61(4):452-467

Scherer, F. M. (1976). Industrial structure, scale economics and worker alienation. In R. T. Mason \& P. D. Qualls (Eds.), essays on industrial Organization in Honor of Joe S. Bain. Cambridge, MA: Ballinger

Skalli A, Theodossiou I, Vasileiou E (2008) Jobs as Lancaster goods: facets of job satisfaction and overall job satisfaction. Journal of Socio-Economics 37(5):1906-1920

Sousa-Poza A, Souza-Posa AA (2003) Gender differences in job satisfaction in Great Britain, 1991-2000: permanent or transitory? Applied Economic Letters 10(11):691-694

Tebaldi E, Elmslie B (2006) Sexual orientation and labour supply. Appl Econ 38(5):549-562

Weichselbaumer D (2003) Sexual orientation discrimination in hiring. Labour Econ 10(6):629-642

Weichselbaumer D (2004) Is it sex or personality? The impact of sex stereotypes on discrimination in applicant selection. East Econ J 30(2):159-186

Publisher's Note Springer Nature remains neutral with regard to jurisdictional claims in published maps and institutional affiliations. 